\title{
Don't keep blaming nurse education .....
}

\section{Alison Twycross}

Correspondence to: Alison Twycross

Faculty of Health and Social Care Sciences, Kingston University and St George's, University of London, 2nd Floor Grosvenor Wing, Cranmer Terrace, London, SW17 ORE, UK; A.Twycross@sgul.kingston. ac.uk occurred by chance.
There are several issues that really irritate me. One is when statistics are presented on the national Ten 0'clock News along with a statement such as the number of violent crimes has increased dramatically in the last year without statistical data to evidence the claim. As Dorothy Forbes outlines in the Research Made Simple paper in this edition it is important to explore the statistical probability or $\mathrm{p}$ values of data to ensure that findings have not

Another concern is that when a report on substandard nursing care is published, nurse education always seems to be blamed for being too academic and not linking theory to practice sufficiently. I am not saying that education does not have a role to play but nursing students in the UK spend 50\% of their time in practice. Clinical colleagues have to be held responsible for poor practice too.

Evidence that nurses learn by role-modelling senior staff has been found in several studies. Novice nurses $(n=15)$ in Taylor's study commented that 'they just followed the (more experienced) nurse's lead." Student nurses ( $\mathrm{n}=99$ ), interviewed by Fitzpatrick et al, discussed modelling their practices on those of more experienced nurses. ${ }^{2}$ In Twycross' study, two participants indicated they had learnt about pain management by observing/ working with more senior staff, and another participant reported she had had no formal education 'except what I picked up as I have gone along.' If nurses learn by copying the behaviours of senior staff, the quality of their practice will obviously depend on those of the role-model.

Professional socialisation also plays a part in perpetuating non-evidenced based practice. When starting a new placement or job, nurses undergo a period of socialisation, during which they learn the rules (formal and informal) that guide staff behaviour. Students $(n=17)$, in one study, indicated there were rewards for conforming to the norms of the ward, such as the increased likelihood of a good placement and feeling part of the team. ${ }^{4}$ In another study, nurses $(n=18)$ indicated that if they did not conform to unit norms they were excluded, shouted at and bullied. ${ }^{5}$ Two studies examining moving and handling practices found nurses did not use their knowledge in practice but rather conformed to ward practices. ${ }^{67}$ More recently, Mooney found that newly qualified nurses' $(n=12)$ willingness to become professionally socialised determined the ease with which they survived in clinical practice. ${ }^{8}$ A nurse's need to fit in may mean they adopt the ward's (poor) practices even if they know this practice is not evidence-based.
Role-modelling suboptimal practices and adopting a unit's formal and informal rules offer alternative and/or additional factors that need considering when reports of poor care hit the headlines. The limited time and money allocated to nurses' professional development in the current financial climate is not going to help the situation described above. Personally, an increasing number of my masters students are having their funding and study leave withdrawn. I am sure I am not alone in this. Perhaps the media could campaign for an appropriate allocation of resources to enable nurses to undertake professional development? Nurses also need time out to reflect on practice and identify areas for change. This was one reason clinical supervision was rolled out. ${ }^{9}$ However, the reality is that there is little time for such activities in today's health service. Next time there is a news report about poor nursing practice I would like to see the media consider some of the issues outlined here such as professional socialisation and limited training opportunities rather than placing the blame solely on nurse education.

\section{Competing interests None.}

\section{References}

1. Taylor C. Problem solving in clinical nursing practice. J Adv Nurs 1997;26:329-36.

2. Fitzpatrick JM, While AE, Roberts JD. Key influences on the professional socialisation and practice of students undertaking different pre-registration nurse education programmes in the United Kingdom. Int J Nurs Stud 1996;33:506-18.

3. Twycross A. Children's Nurses' Pain Management Practices: Theoretical Knowledge, Perceived Importance and DecisionMaking, Unpublished PhD Thesis, University of Central Lancashire, 2004.

4. Gray M, Smith LN. The professional socialization of diploma of higher education in nursing students (Project 2000): a longitudinal study. J Adv Nurs 1999;29:639-47.

5. Philpin SM. The impact of 'Project 2000' educational reforms on the occupational socialization of nurses: an exploratory study. J Adv Nurs 1999;29:1326-31.

6. Kneafsey R. The effect of occupational socialization in nurses patient handling practices. J Clin Nurs 2000;9:585-93.

7. Swain J, Pufahl E, Williamson GR. Do they practice what we teach? A survey of manual handling practice. J Clin Nurs 2003;12:297-306.

8. Mooney M. Professional socialisation: the key to survival as newly qualified nurses. Int J Nurs Pract 2007;13:75-80.

9. Nursing and Midwifery Council. Clinical Supervision for Registered Nurses. London: NMC 2008. 